\title{
Modelling the global atmospheric transport and deposition of radionuclides from the Fukushima Dai-ichi nuclear accident
}

\author{
T. Christoudias ${ }^{1}$ and J. Lelieveld ${ }^{1,2}$ \\ ${ }^{1}$ The Cyprus Institute, Nicosia, Cyprus \\ ${ }^{2}$ Max Planck Institute of Chemistry, Mainz, Germany \\ Correspondence to: T. Christoudias (christoudias@cyi.ac.cy) \\ Received: 24 August 2012 - Published in Atmos. Chem. Phys. Discuss.: 19 September 2012 \\ Revised: 7 January 2013 - Accepted: 22 January 2013 - Published: 5 February 2013
}

\begin{abstract}
We modeled the global atmospheric dispersion and deposition of radionuclides released from the Fukushima Dai-ichi nuclear power plant accident. The EMAC atmospheric chemistry - general circulation model was used, with circulation dynamics nudged towards ERA-Interim reanalysis data. We applied a resolution of approximately 0.5 degrees in latitude and longitude (T255). The model accounts for emissions and transport of the radioactive isotopes ${ }^{131} \mathrm{I}$ and ${ }^{137} \mathrm{Cs}$, and removal processes through precipitation, particle sedimentation and dry deposition. In addition, we simulated the release of ${ }^{133} \mathrm{Xe}$, a noble gas that can be regarded as a passive transport tracer of contaminated air. The source terms are based on Chino et al. (2011) and Stohl et al. (2012); especially the emission estimates of ${ }^{131} \mathrm{I}$ are associated with a high degree of uncertainty. The calculated concentrations have been compared to station observations by the Comprehensive Nuclear-Test-Ban Treaty Organisation (CTBTO). We calculated that about $80 \%$ of the radioactivity from Fukushima which was released to the atmosphere deposited into the Pacific Ocean. In Japan a large inhabited land area was contaminated by more than $40 \mathrm{kBqm}^{-2}$. We also estimated the inhalation and 50 -year dose by ${ }^{137} \mathrm{Cs},{ }^{134} \mathrm{Cs}$ and ${ }^{131}$ I to which the people in Japan are exposed.
\end{abstract}

\section{Introduction}

On the 11 March 2011 an earthquake occurred off the Pacific coast of Tōhoku, which triggered a powerful tsunami. The tsunami damaged the Fukushima Dai-ichi nuclear power plant complex, followed by a series of major accidents, giving rise to three INES (International Nuclear Event Scale) level 7 events. This caused the release of large amounts of radionuclides to the atmosphere (Butler, 2011; Chino et al., 2011; Stohl et al., 2012). In particular the isotopes of iodine and caesium adversely affect human health through the large-scale contamination of air, water, soils and agricultural products (Anspaugh et al., 1988). Although both radionuclides are released as gases, caesium has a low volatility and partitions into ambient aerosol particles, whereas in our model iodine largely remains in the gas phase. Removal of these compounds from the atmosphere is governed by dry and wet deposition processes. Several initial studies of the atmospheric behaviour and budgets of radioactive species, notably ${ }^{131} \mathrm{I}$ and ${ }^{137} \mathrm{Cs}$, were conducted using chemistry transport models. For example, the Austrian Weather Service (ZAMG) performed a daily forecast of the dispersion of radioactivity in the atmosphere. Morino et al. (2011) simulated the transport and deposition of the radionuclides over Japan using an off-line regional model. A numerical simulation for the long-range transport from the plant to the US and even Europe with a global aerosol transport model was conducted by Takemura et al. (2011). Ten Hoeve and Jacobson (2012) quantified worldwide health effects using the GATOR-GCMOM global model.

The objective of the present study is to model the global atmospheric dispersion of radionuclides from the Fukushima accident and compute the deposition patterns using an atmospheric chemistry-general circulation model, initialized by estimated source terms. The emission strengths have been determined through inverse modelling by Stohl et al. (2012). The temporal emission profiles of the radioactive isotopes ${ }^{133} \mathrm{Xe}$ and ${ }^{137} \mathrm{Cs}$ were estimated at three reference release heights using the Lagrangian transport model FLEX- 
PART (Stohl et al., 1998), driven by operational meteorological data from the European Centre for Medium-Range Weather Forecasts (ECMWF) and the National Center for Environmental Prediction (NCEP) Global Forecast System (GFS) analyses, and constrained by a large number of available concentration and deposition data from Japan, North America and Europe.

Furthermore, we incorporated the preliminary estimates of release amounts of ${ }^{131} \mathrm{I}$ by Chino et al. (2011). A reverse estimation of the source term was conducted by coupling Japanese Environmental monitoring data with regional atmospheric dispersion simulations. Emission inventories are further discussed in Sect. 2.1.

We briefly describe the model in Sect. 2, including the emissions of radionuclides and the representation of removal mechanisms. The analysis of our results regarding the global deposition (Sect. 3.2) and a comparison of surface concentrations to station measurements (Sect. 3.1) are discussed in Sect. 3. Estimates of doses from the inhalation and ground deposition of radionuclides are given in Sect. 3.3. A summary and conclusions are presented in Sect. 4.

\section{Model simulation}

The global ECHAM5/MESSy Atmospheric Chemistry (EMAC) general circulation model includes sub-models describing tropospheric and middle atmospheric processes and their interactions with oceans, land and vegetation, and trace species emissions of natural and anthropogenic origin (Jöckel et al., 2005). It uses the first version of the Modular Earth Submodel System (MESSy1) to link multi-institutional computer codes. The core atmospheric model is the 5th generation European Centre Hamburg general circulation model (ECHAM5; Roeckner et al., 2003, 2006).

For the present study we applied EMAC version 1.9 (based on ECHAM5 version 5.3) at the T255L31 resolution, i.e., with a spherical spectral truncation of T255 (corresponding to a quadratic Gaussian grid of approximately 0.5 by 0.5 degrees in latitude and longitude) with 31 vertical hybrid pressure levels up to $10 \mathrm{hPa}$, a time step of two minutes and threehourly output. To test the effects of model resolution on the simulation we repeated the study on the reduced T106L31 resolution (corresponding to a quadratic Gaussian grid of about 1.1 by 1.1 degrees). Our simulation spans the period of 1 March-31 May 2011.

The large-scale component of the model circulation dynamics was nudged by applying a Newtonian relaxation (Jeuken et al., 1996) towards the European Centre for Medium-range Weather Forecasts (ECMWF) ERA-Interim reanalysis data (Simmons et al., 2007), produced at T255 resolution, to realistically represent the tropospheric meteorology of the simulated period. The nudged variables are vorticity, divergence, temperature and surface pressure (Lelieveld et al., 2007), whereas the hydrological cycle is computed freely and consistently according to the model dynamics. Therefore, the precipitation field is not necessarily identical with that of the ERA-Interim dataset, which is relevant for the transport and wet deposition of soluble tracers, notably ${ }^{137}$ Cs. In Fig. 1 we present a comparison between the time integrated precipitation from ERA-Interim and our model over the simulated period from 11 March onward. It shows that precipitation patterns downwind of Japan are very similar, whereas in the tropics (e.g., the intertropical convergence zone) differences are more evident. We do not expect that this significantly influences our results. Both ERA-Interim and EMAC results indicate that during the first week after the accident (11-18 March 2011; Fig. 1) some precipitation occurred in the northern part of the main island of Japan, mainly along the east coast $\left(37^{\circ}-40^{\circ} \mathrm{N}\right)$.

The applied model setup comprises the submodels RAD4ALL for radiation and atmospheric heating processes, CLOUD for cloud formation and microphysical processes including precipitation, and CONVECT for the vertical transports of trace species associated with convection. The DRYDEP (Kerkweg et al., 2006) and SCAV (Tost et al., 2006, 2007) submodels were used to simulate aerosol dry and wet deposition processes, respectively. The SEDI submodel was used to simulate particle sedimentation, of which the results will be presented below as part of the simulated dry deposition.

We focus on the radionuclides that were emitted as gases and partly attached to ambient aerosol particles: the semivolatile isotopes of iodine ${ }^{131}$ I (with a half-life of 8 days) and caesium ${ }^{137} \mathrm{Cs}$ (with a half-life of $\sim 30$ years). We also modeled the emission of the isotope ${ }^{133} \mathrm{Xe}$ (with a half-life of 5.25 days). Since xenon is an unreactive noble gas and is not removed by deposition processes, it serves as a passive tracer of atmospheric transport. ${ }^{137} \mathrm{Cs}$ is modeled as a watersoluble aerosol with a standard lognormal distribution with mean radius $0.25 \mu \mathrm{m}$ and a Henry's law coefficient equal to $1.0 \mathrm{molL}^{-1} \mathrm{~atm}^{-1}$ and a density of $1000.0 \mathrm{~kg} \mathrm{~m}^{-3}$. Due to the long decay lifetime of ${ }^{137} \mathrm{Cs}$ compared to the simulation period and the short timescales of the atmospheric removal processes considered, its radioactive decay is not taken into account in the simulation.

\subsection{Emissions}

We used the temporal emission patterns for the radioactive isotopes ${ }^{133} \mathrm{Xe}$ and ${ }^{137} \mathrm{Cs}$ for March and April 2011, estimated based on an inverse modelling method, applying the transport model FLEXPART, by Stohl et al. (2012). The first guess for the a priori emissions was based on fuel events and documented accident events. Measurement data of both atmospheric activity concentrations and bulk deposition from several stations in Japan, North America and other regions were used to provide subsequently improved estimates by inverse modeling. Tracers are emitted within three atmospheric layers over the Fukushima Dai-ichi power plant 

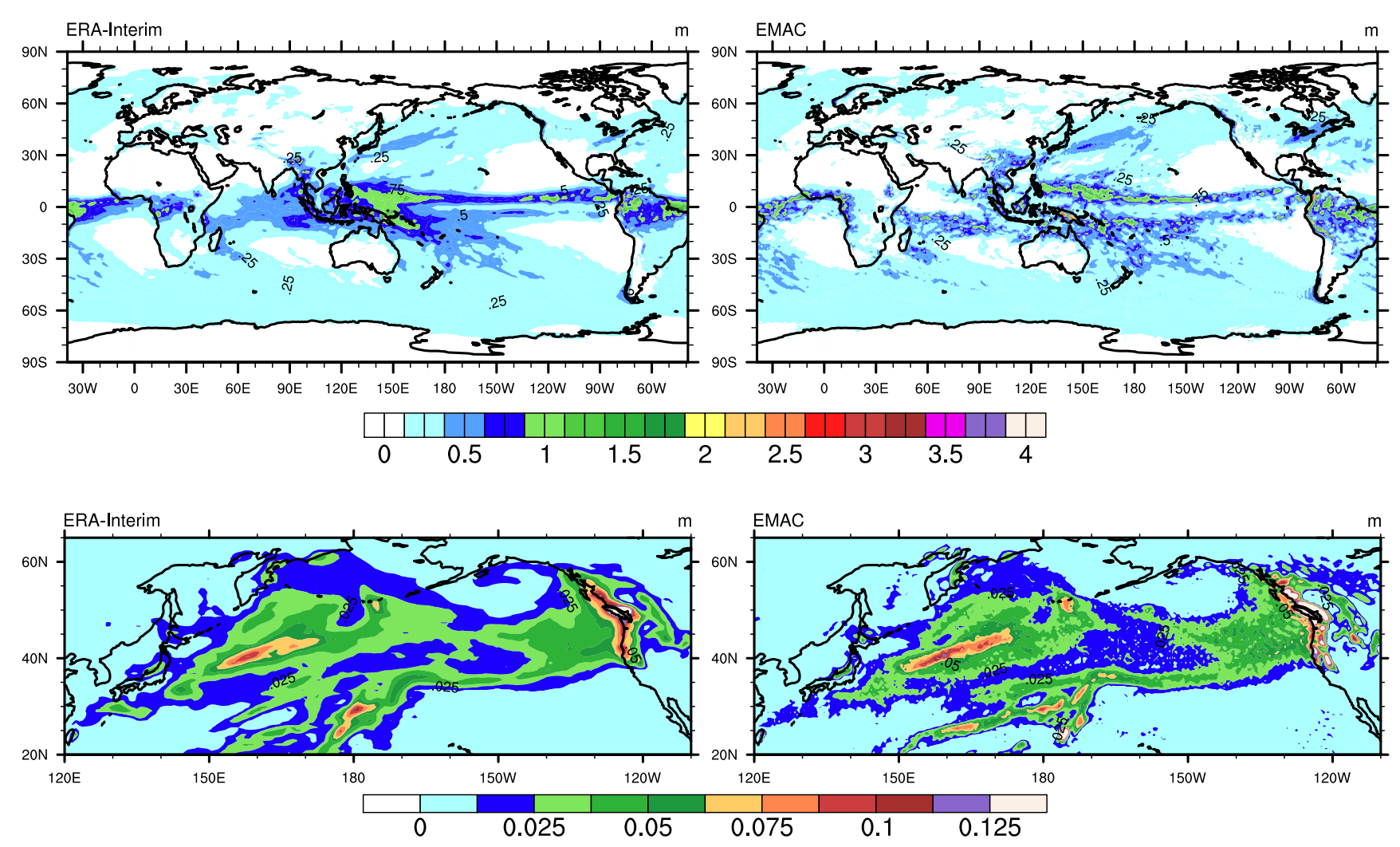

Fig. 1. Time integrated precipitation (in m) patterns over the period 11 March-31 May 2011 computed with the EMAC model (upper right) compared to the ERA-Interim data (upper left). The lower panels show the precipitation during the first week after the accident (11-18 March 2011).

(which extend up to 50, 300 and $1000 \mathrm{~m}$ ). Emission inventories are provided by Stohl et al. (2012) and used in our study between the 10 March and the 20 April 2011.

The estimates are reported to be sensitive to replacing the GFS meteorological data with ECMWF data with a sensitivity equal to scaling the a posteriori total emissions estimate by $104 \%$ for ${ }^{133} \mathrm{Xe}$ and $68 \%$ for ${ }^{137} \mathrm{Cs}$. When using only deposition, based on Japanese and non-Japanese data, the sensitivity scaling factors of the a posteriori total emissions are reported to be $55 \%, 59 \%$ and $150 \%$ respectively. The total amount of ${ }^{137} \mathrm{Cs}$ emitted is $36.7(20.1-53.1) \mathrm{PBq}$, and of ${ }^{133} \mathrm{Xe} 15.3$ (12.2-18.3) EBq (Stohl et al., 2012). Although we did not explicitly include the emissions of ${ }^{134} \mathrm{Cs}$, in Sects. 3.2 and 3.3 we will discuss the deposition of this compound by assuming a scaling factor to $137 \mathrm{Cs}$ suggested by Ten Hoeve and Jacobson (2012).

We also incorporated in our model preliminary emission estimates of the released amounts of ${ }^{131} \mathrm{I}$ (in total $150 \mathrm{PBq}$ ) and ${ }^{137} \mathrm{Cs}$ (in total $13 \mathrm{PBq}$ ) by Chino et al. (2011), based on the reverse estimation of the source term by coupling Japanese environmental monitoring data with regional atmospheric dispersion simulations. The System for Prediction of Environmental Emergency Dose Information (SPEEDI; Chino et al., 1993) network system, operated by the Japanese
Ministry of Education, Culture, Sports, Science and Technology (MEXT, 2011), was used to calculate dose rates and atmospheric concentrations.

The emission inventory compiled by Chino et al. (2011) used Japanese environmental monitoring station data within a regional simulation domain. The calculations assumed constant radioactivity ratios for the different radionuclides based on iodine and caesium concentrations in rain, snow and vegetation in the area. By taking into account these factors and a number of assumptions used in their simulation, Chino et al. (2011) estimate that their emission inventory is associated with an error of at least a factor of five. This uncertainty is taken into account in our model of the deposition of radionuclides by conducting a sensitivity study with 5 times higher emissions, discussed in Sect. 3.2.

The preliminary initial emission estimates by Chino et al. (2011) were superseded by revised estimates published by Katata et al. (2012) based on additionally disclosed environmental monitoring data for air dose rates and concentrations of radionuclides from four stations during the early phase of the accident, from the morning of 12 March to late night 14 March. Major releases of high-concentration plumes during this period, which were not taken into account in Chino et al. (2011), significantly increased the amount of dry deposition 

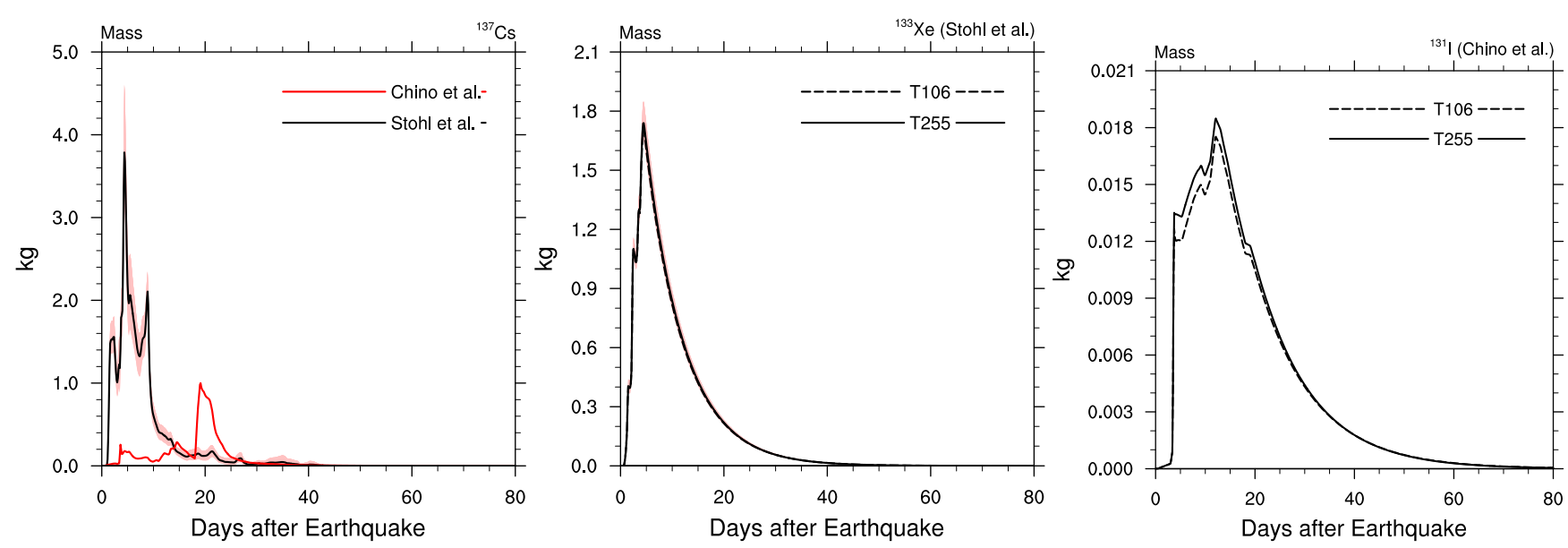

Fig. 2. Total atmospheric content (in kg) of ${ }^{137} \mathrm{Cs}$ (left) and ${ }^{133} \mathrm{Xe}$ (middle) and ${ }^{131} \mathrm{I}$ (right) that originated from Fukushima Dai-ichi based on the emissions inventories by Stohl et al. (2012) and Chino et al. (2011). The red bands indicate the reported range of the emission source estimates, and the dashed lines correspond to the results of the T106 horizontal resolution simulation.

and air dose rates. The preliminary and revised estimates of the source term were verified and refined in Terada et al. (2012) and found to be reasonable, within the large uncertainties (order of factor 5), over the period when the plume dispersed over land, which could not be verified over the period when the plume travelled over the ocean. The refinements of the results by Chino et al. (2011) are not included in our study.

A comparison of the estimate of released ${ }^{137} \mathrm{Cs}$ by Stohl et al. (2012) and Chino et al. (2011) can be seen in the total model calculated atmospheric content (Fig. 2) and for individual station measurements (Figs. 3-5). The two emission estimates differ greatly, both in magnitude and time profile. We find that the spatial resolution of our model has little impact on the global atmospheric content of radionuclides.

\section{Results}

The comparison of our model results with station measurements is discussed in Sect. 3.1. The modeled global deposition of radionuclides is presented in Sect. 3.2. The doses to the public from deposition and inhalation based on our results are calculated in Sect. 3.3.

\subsection{Comparison with Station Measurements}

The Comprehensive Nuclear-Test-Ban Treaty (CTBT), adopted by the United Nations General Assembly, foresees a ban of all nuclear explosions. For compliance, a global International Monitoring System (IMS) of measurement technologies has been established by the CTBT Organization (CTBTO), with data delivered to the International Data Centre for of the CTBTO Preparatory commission in Vienna, Austria. The IMS comprises radionuclide measurement stations with continuous coverage, distributed around the globe.
The subset of stations with available measurements used in our study can be seen in Figs. 3 and 4.

The stations operate high volume aerosol samplers using collection filters with a minimum detection capability (MDC) range typically between $1-10 \mu \mathrm{Bq} \mathrm{m}^{-3}$ for Cs. Since iodine largely travels in the gas phase, the filter measurements represent only a small fraction of airborne ${ }^{131} \mathrm{I}$, thus associated with a relatively large measurement uncertainty (Stoehlker et al., 2011). Only $20-50 \%$ of ${ }^{131}$ I is collected in the samples, since the IMS stations are using paper filters through which part of the iodine passes unattenuated (as reported by the CTBTO Virtual Data Exploitation Centre). Noble gas concentration measurement stations are also been set up worldwide, with ${ }^{133} \mathrm{Xe}$ being the most important and prevalent isotope. It is measured with typical MDC of about $0.2 \mathrm{mBq} \mathrm{m}^{-3}$. The CTBTO station measurements of radionuclide concentrations can be directly compared to the concentrations simulated by our model.

There are some additional aspects that affect the CTBTO station measurements, which should be taken into account when comparing to the model simulations (Stoehlker et al., 2011). The highest concentrations of Xe after the accident were outside the dynamic range of the noble gas system, so detections that are higher than $100 \mathrm{Bqm}^{-3}$ are not expected to be accurate. It is also known that the Takasaki (JPX38) noble gas station in Japan was affected significantly by dead time in the first three weeks after the accident. The Japanese particulate station JPP38, also at Takasaki, was affected by radioactive leaks into the measurement room and power outages between 14 and 16 March 2011. Contamination at JPP38 lead to an overestimation of ${ }^{137} \mathrm{Cs}$ concentrations by about $1 \mathrm{mBqm}^{-3}$ until August 2011. Similar contamination occurred at USP71 at Sand Point, Alaska, USA, leading to an overestimation in the range of $3 \mu \mathrm{Bq} \mathrm{m}^{-3}$ for 

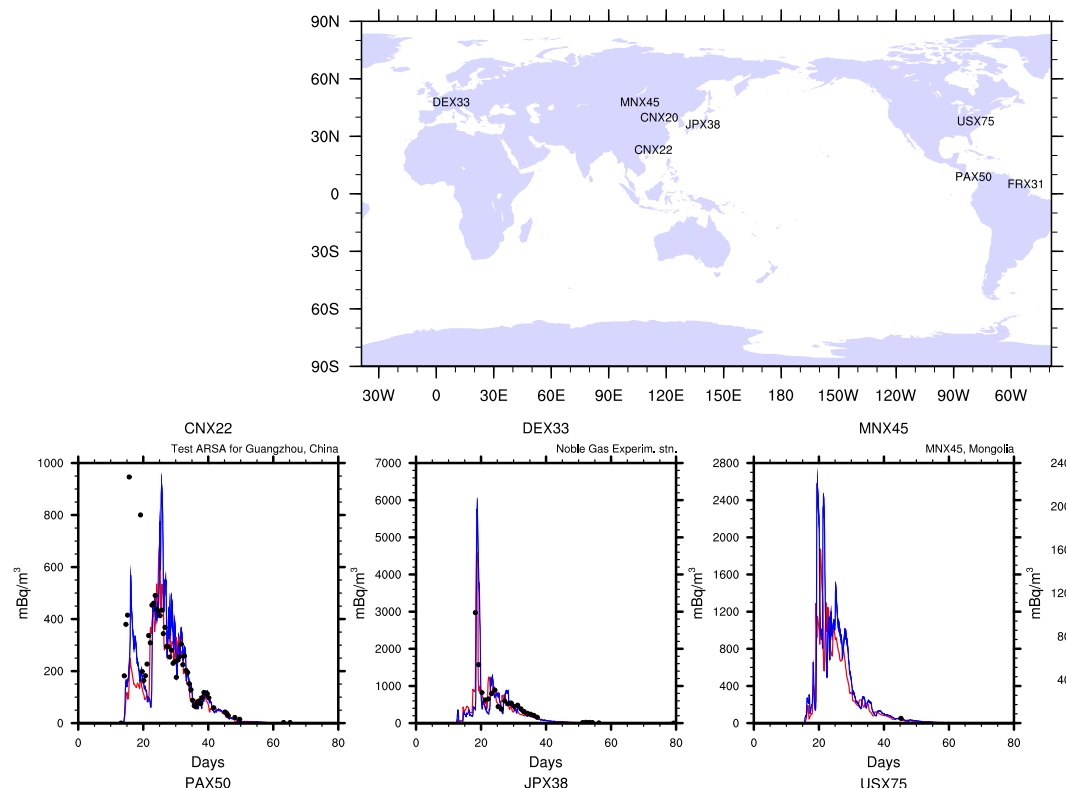

MNX45
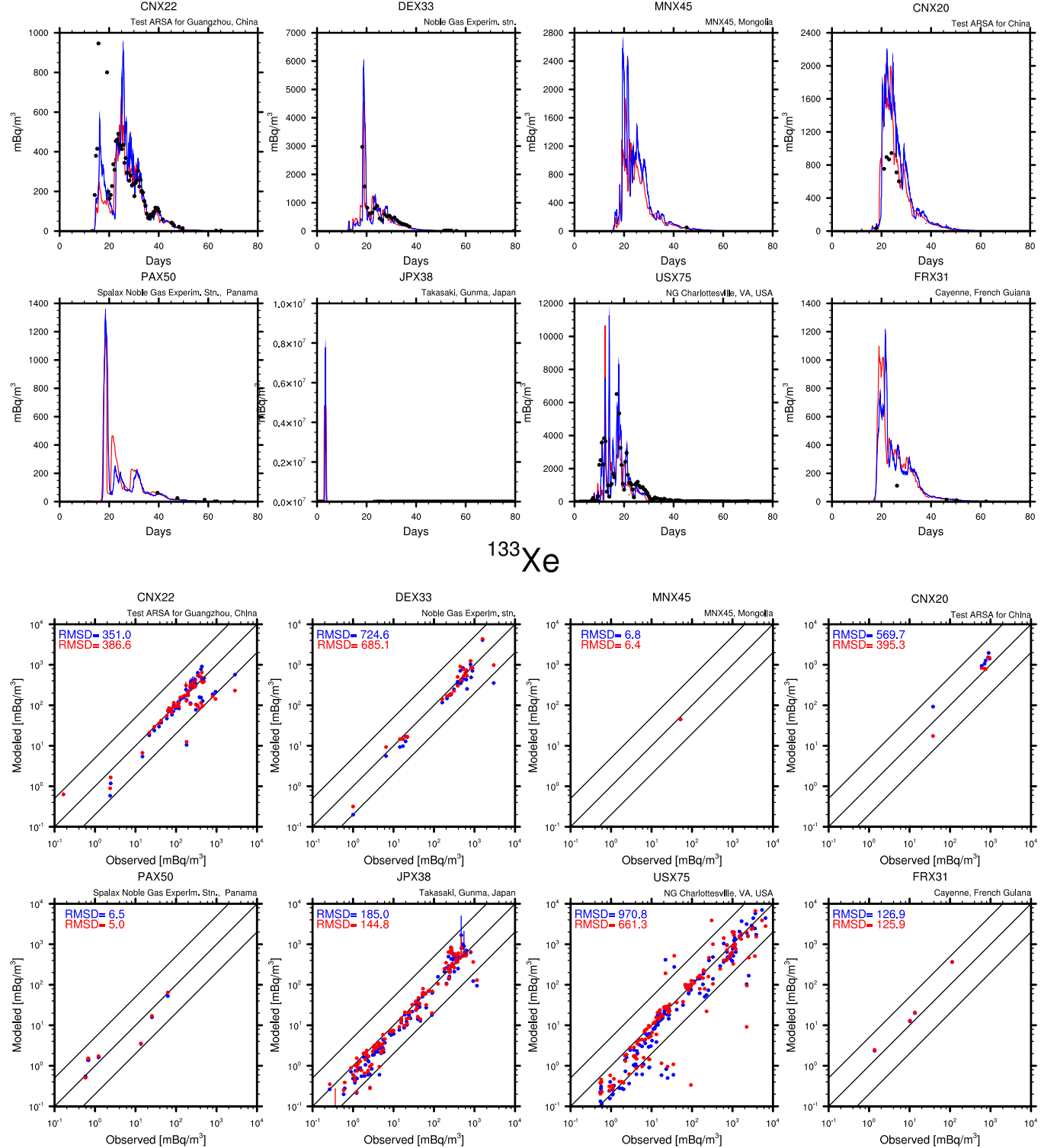

Fig. 3. Top: CTBTO measurement network station location and code for the noble gas ${ }^{133} \mathrm{Xe}$ for the subset of stations with measurements available used in our study.

Middle: Observed (black points) and modeled (solid lines) surface concentrations of ${ }^{133} \mathrm{Xe}$ at the eight stations. T255 horizontal resolution is shown in blue and T106 in red. The time axis represents days after the accident.

Bottom: Modeled versus observed surface concentrations of ${ }^{133} \mathrm{Xe}$ at the eight stations. The diagonal lines represent the 1:1 ratio and the factor of 5 over- and underestimates. 
${ }^{137} \mathrm{Cs}$. Therefore, for these locations we expect our model to underestimate the reported observations.

The locations of the CTBTO measurement stations for radionuclide gases and particulates used for comparison, including station codes, can be seen in Fig. 4. In total, eight stations are available for noble gas observations and 37 for particulates. The availability of 3 months of measurements allows for the comparison over a wide range of meteorological conditions and radionuclide concentrations at each station location.

We focus on the concentrations of radionuclides in the lowest layer of our model and in the grid boxes where the stations are located, and compare with the measured concentrations at each station at the nearest model output time step to the station collection start time. The comparison for all ${ }^{133} \mathrm{Xe}$ stations is presented in Fig. 3 and selected stations for ${ }^{137} \mathrm{Cs}$ and ${ }^{131} \mathrm{I}$ in Figs. 4 and 5, respectively. The entire set of measurements and concomitant model results is presented in the electronic supplement. Our model does not take into account the resuspension of particles after they have been deposited, though we expect the effect to be small.

Overall, there is good coincidence of the time of first arrival of the radionuclide plume at the station and the time of first detection of radioactivity at a station, especially for stations in the Asia-Pacific and North American regions, taking into account coincidence timing uncertainties. As all the stations collect samples over a period of typically $12 \mathrm{~h}$ or more for each measurement performed, there is an associated uncertainty of the same order of magnitude over the time of first arrival of radionuclides from Fukushima at each measurement location. Furthermore, the measurement record is not continuous for all stations, resulting in cases where there is no observational coverage of the model prediction of the arrival of radionulcide plumes. Good agreement is obtained for the inert noble gas ${ }^{133} \mathrm{Xe}$ (although only a limited number of stations is available). The agreement is not as good for ${ }^{137} \mathrm{Cs}$ and ${ }^{131} \mathrm{I}$. This is to be expected as the greater extend to which different removal processes are involved (dry and wet deposition and sedimentation), creates larger uncertainties in the source estimates and in the modelling of atmospheric transport and removal. These removal processes take place on a sub-grid scale and are therefore parameterized and thus less explicitly resolved by the model than atmospheric dynamical and transport processes. Especially the model representation of precipitation is critical for the simulation of wet deposition. It is notable that the results of the higher resolution T255 calculations are not systematically more consistent with the measurements than the lower resolution T106 results. The lower panels of Figs. 3, 4, and 5 present the root-mean-square-deviations (RMSDs) between the measurements and model results for both resolutions. We also computed the normalised RMSDs, and find that they are typically below $50 \%$, irrespective of the distance between the station and the emission source.
For the eight stations available with varying number of measurements, there is good agreement between the model results and the measurements for the noble gas ${ }^{133} \mathrm{Xe}$, both for the higher and lower resolution (Fig. 3). Nevertheless, the modeled concentrations at JPX38 (Takasaki, Gunma, Japan) peak in March at values well outside the dynamic range of the measurement instruments. All measurements at the other stations are below $100 \mathrm{mBq} \mathrm{m}^{-3}$, the reported upper range of the observation accuracy. The model not only represents the measurements well in the vicinity of the source, but also in North, Middle and South America (stations USX75, PAX50, FRX31), and even as far downwind as Germany (DEX33). Again, there are no indications that the higher resolution version of the model performs systematically better. Even though the ERA-Interim data, used to nudge the model to the actual meteorology, are produced at T255 resolution, the regridding of the data to the coarser T106 resolution seems to have little effect on the quality of the dynamics simulations.

For the comparison of the model simulation results to observations of the surface concentrations of ${ }^{137} \mathrm{Cs}$ (Fig. 4), reduced though nevertheless reasonable agreement can be claimed, taking into account the inherent uncertainties based on the multitude and the complexity of the simulated removal processes (sedimentation, dry and wet deposition). In most cases there is close coincidence between the modeled and observed time of arrival of the first radioactive plume at the station and most model results fall within the factor of five range of the measurements (Fig. 4). However, our model shows the arrival of high concentrations of radioactive aerosols in the Asia-Pacific region (see for example USP80 at Upi, Guam, in the supplement, and PHP52 in Tanay, the Philippines, in Fig. 4), which are not reflected in the station observations. There is clearly reduced agreement compared to the results for the noble gas ${ }^{133} \mathrm{Xe}$, which we attribute to the additional uncertainties related to the simulation of removal processes, in particular by precipitation. These types of uncertainties also affect the source estimates obtained by inverse modelling, e.g. by Stohl et al. (2012).

To determine the total level of airborne ${ }^{131}$ I concentrations, both the gaseous and particulate fractions of ${ }^{131} \mathrm{I}$ must be accounted for. Sampling gaseous radio-iodine requires activated charcoal traps, which are not implemented in the IMS network, as they are not required for CTBT monitoring (Stoehlker et al., 2011). Therefore, the iodine measurements should be understood as a lower bound, as only the aerosol phase can be collected on particle filters (Winiarek et al., 2012). Based on data by the "Ring of Five (Ro5)", an informal network of European national authorities (which comprises more than 150 sampling systems of high volume samplers and some with activated coal traps), the average gaseous/total ratio for ${ }^{131} \mathrm{I}$ is $77.2 \pm 13.6 \%$ (Masson et al., 2011). The US Environmental Protection Agency (EPA) RadNet station measurements detected $81 \%$ of the ambient ${ }^{131} \mathrm{I}$ in the gas and $19 \%$ in the particle phase (Ten Hoeve and Jacobson, 2012). These values are close to the 

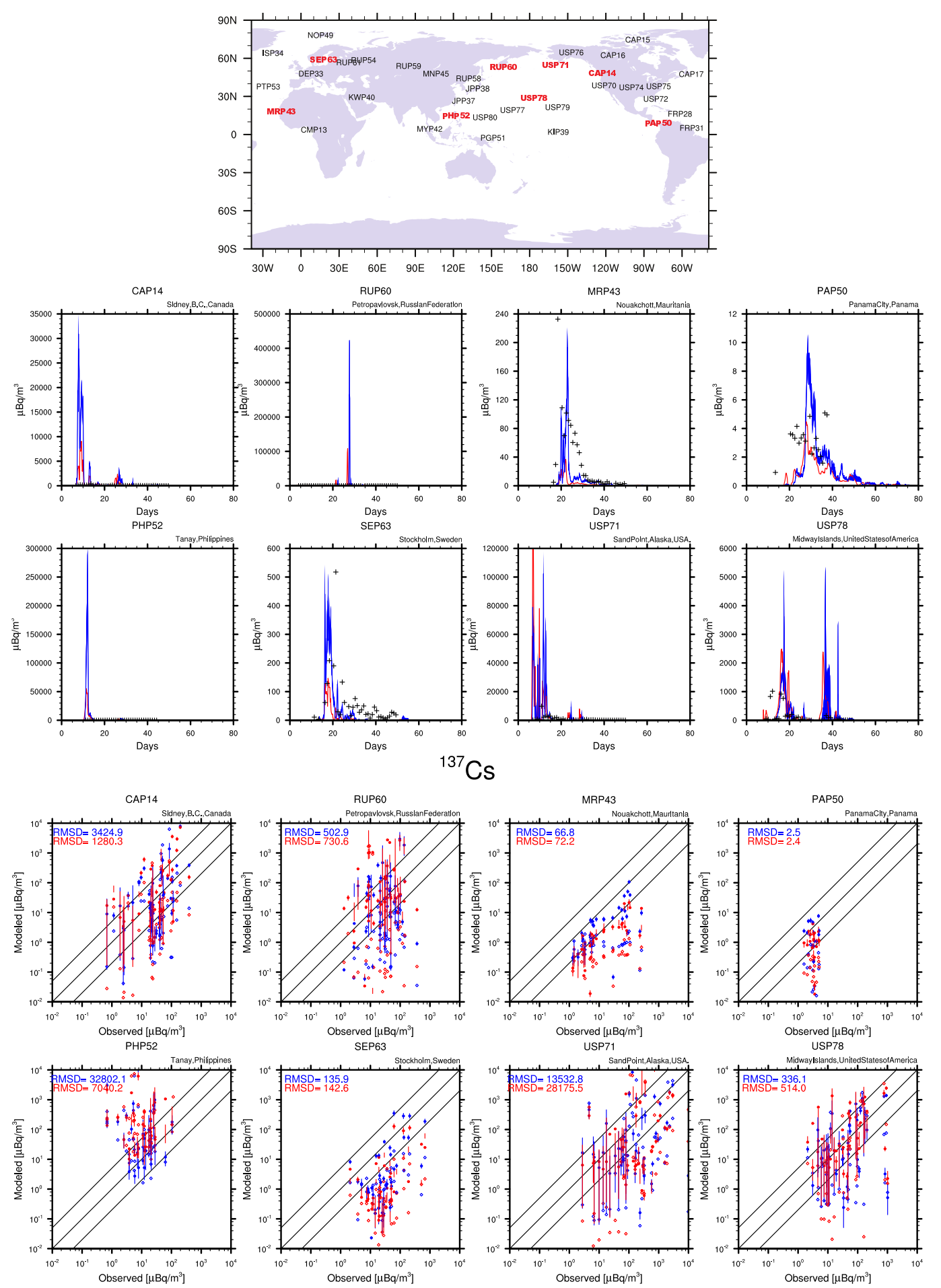

Fig. 4. Top: CTBTO measurement network station location and code for ${ }^{137} \mathrm{Cs}$ for the subset of stations with measurements available used in our study. Stations shown in our study are highlighted in red.

Middle: Observed (black crosses) and modeled (solid lines) surface concentrations of ${ }^{137} \mathrm{Cs}$ at the eight selected stations. T255 horizontal resolution is shown in blue and T106 in red. The time axis represents days after the accident.

Bottom: Modeled (Stoehlker et al. (2011) - solid circles; Chino et al. (2011) - open rhombi) versus observed surface concentrations of ${ }^{137} \mathrm{Cs}$ at the eight stations. The diagonal lines represent the 1:1 ratio and the factor of 5 over- and underestimates. 

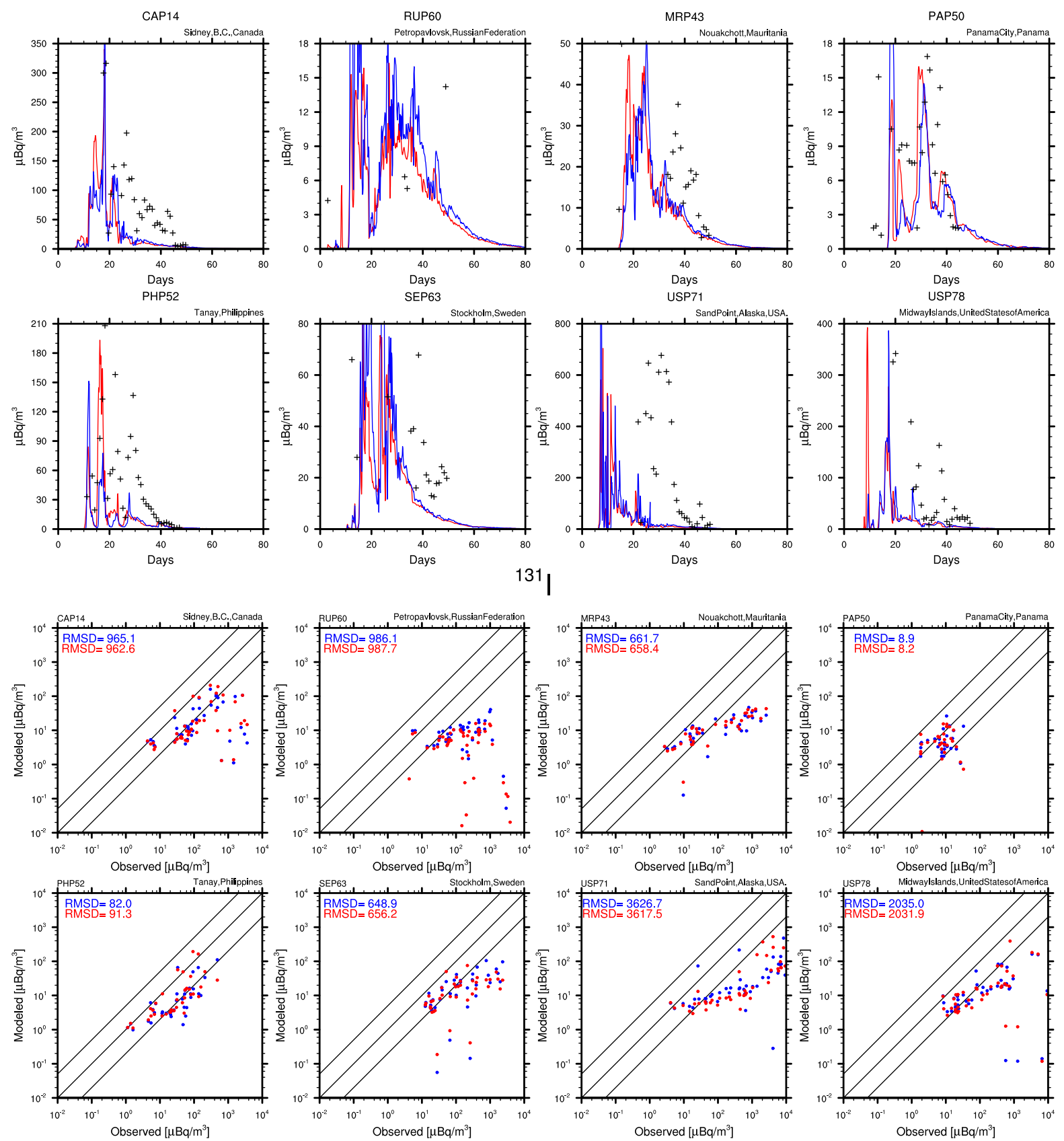

Fig. 5. Top: Observed (black points) and modeled (solid lines) surface concentrations of ${ }^{131}$ I at eight selected stations. The station locations are the same as in Fig. 4. Due to the limited collection efficiency of the filter sampling of ${ }^{131} \mathrm{I}$, the observations represent about $20-50 \%$ of the ambient concentrations. T255 horizontal resolution is shown in blue and T106 in red. The time axis represents days after the accident. Bottom: Modeled versus observed surface concentrations of ${ }^{131} \mathrm{I}$ at the eight stations. The diagonal lines represent the $1: 1$ ratio and the factor of 5 over- and underestimates.

average reported value for the Chernobyl accident by Hilton et al. (1991) and the average of $71 \pm 11 \%$ reported from the Fukushima site from 22 March to 4 April 2011 (Stoehlker et al., 2011). Therefore, a factor of 4 gaseous to particulate fraction seems an appropriate estimate for the partitioning.
As we do not account for the removal of ${ }^{131}$ I via wet deposition, we would expect our model to overestimate the actual ${ }^{131}$ I concentrations. Since only $20-50 \%$ of the ${ }^{131} \mathrm{I}$ is captured on the filters, (as reported by the CTBTO Virtual Data Exploitation Centre) we would also expect that the model more strongly overestimates the measured ${ }^{131} \mathrm{I}$ 

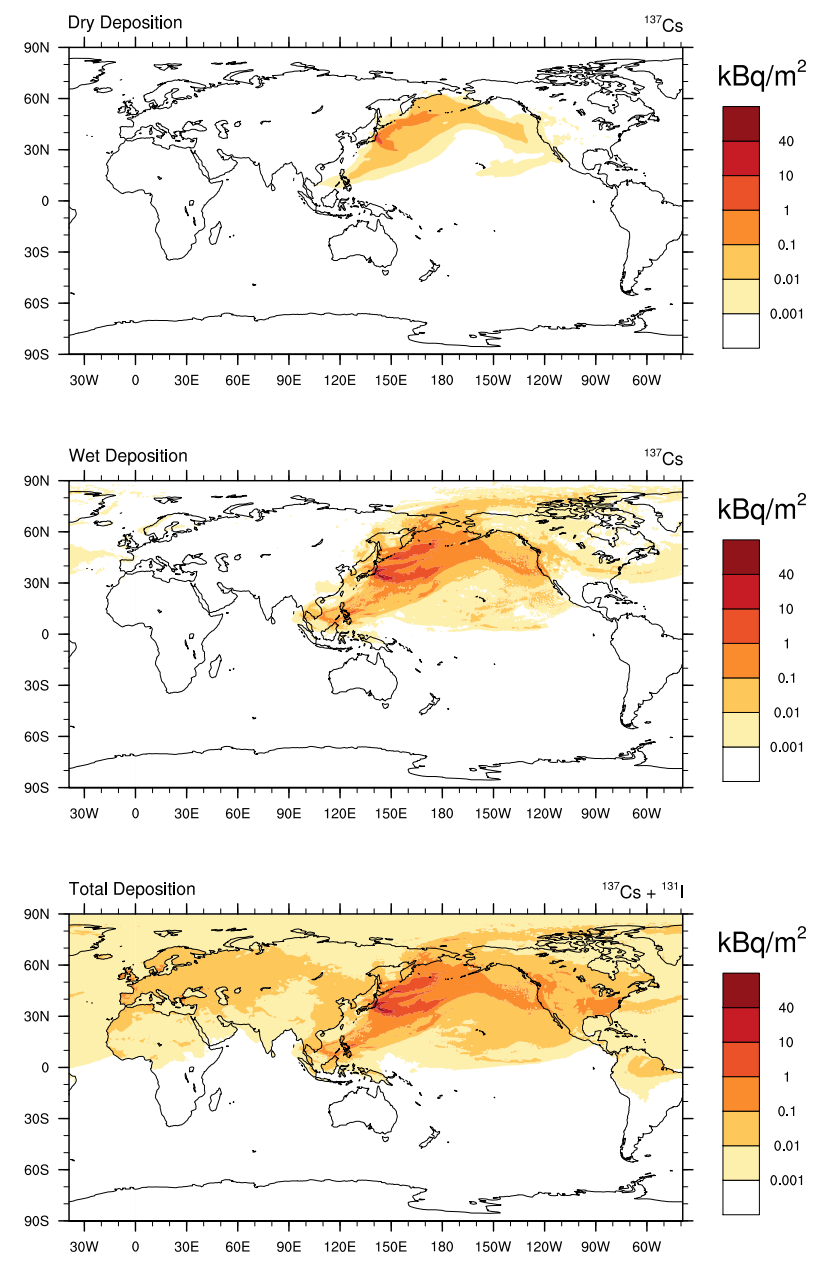

Fig. 6. Global distribution of dry (upper panel) and wet (middle panel) deposition (in $\mathrm{Bq}$ ) of ${ }^{137} \mathrm{Cs}$ and total deposition (bottom panel) of ${ }^{137} \mathrm{Cs}$ and dry deposition of gaseous ${ }^{131} \mathrm{I}$. Contours are on a logarithmic scale.

concentrations. On the contrary, the model tends to generally underestimate the measurements of the atmospheric concentrations of ${ }^{131}$ I based on the emission inventory by Chino et al. (2011) (Fig. 5). Chino et al. (2011) estimate a total release of $150 \mathrm{PBq}$ between 12 March and 6 April 2011, revised in Terada et al. (2012) to $128 \mathrm{PBq}$ between 12 March and 1 May 2011. Both results are considered by their respective authors to be lower estimates and to have an error of at least a factor of five. Winiarek et al. (2012) estimate the lower bound of the total activity of ${ }^{131} \mathrm{I}$ released into the atmosphere between 11 March and 26 March 2011 to be between 190 and $700 \mathrm{PBq}$ (and 190-380 PBq when using the most reliable methods and the Japanese observations only), comparable to the first estimates of $150 \mathrm{PBq}$ by the Nuclear Safety Commission of Japan. Considering that the model typically underestimates measured ${ }^{131} \mathrm{I}$ concentrations, the lower bound estimates mentioned above probably represent
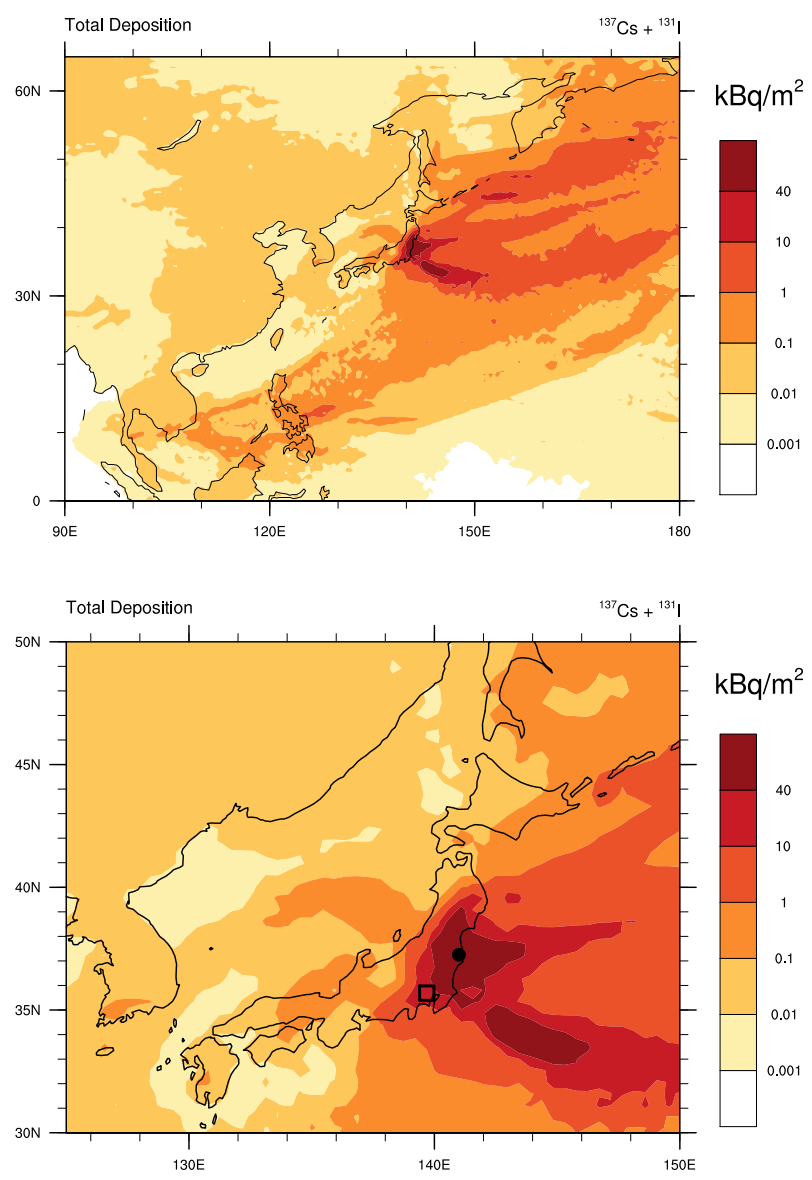

Fig. 7. Regional total deposition of ${ }^{137}$ Cs and dry deposition of gaseous ${ }^{131} \mathrm{I}$ in $\mathrm{Bq}$ at different scales. The black point marks the location of the Fukushima nuclear power plant and the rectangle the Tokyo metropolitan area. Contours are on a logarithmic scale. The $40 \mathrm{kBqm}^{-2}$ contour lines signify areas that received total deposition greater than the contamination activity level defined by International Atomic Energy Agency (IAEA) (2005, 2009).

underestimates of the actual emissions of ${ }^{131} \mathrm{I}$ by at least a factor two to five.

\subsection{Deposition of radionuclides}

In this section we assess the atmospheric budget and deposition patterns of radioactivity by calculating the contributions of different removal processes, i.e., particle sedimentation, dry and wet deposition; the latter through large-scale and convective precipitation. Since the contribution of sedimentation is only small we present it as part of the dry deposition. The global distribution of deposited ${ }^{137} \mathrm{Cs}$ radionuclides is shown in Fig. 6 for dry and wet deposition processes separately (top and middle panel, respectively) based on the emission inventory of Stohl et al. (2012). Following the definition by the International Atomic Energy Agency (IAEA) (2005, 2009), any area with activity $\geq 40 \mathrm{kBq} \mathrm{m}^{-2}$ is considered to 
be contaminated (the most intense red scale). Formally, contamination means the presence of a radioactive substance on a surface in quantities in excess of $\geq 40 \mathrm{kBq} \mathrm{m}^{-2}$ for beta and gamma emitters. Both, ${ }^{137} \mathrm{Cs}$ and ${ }^{131} \mathrm{I}$ are beta and gamma emitters. Since we integrate the deposition over the period after the accident until the end of May 2011, our results represent the accumulated contamination of these two radionuclides.

The prevailing winds during the emission period after 11 March transported most of the radionuclides in easterly direction, away from Japan and the continent. Precipitation events caused the deposition to occur predominantly over the ocean. Figure 6 illustrates that the dry deposition patterns are smoother than of wet deposition, i.e., less dependent on individual meteorological events. It also shows that dry deposition of ${ }^{137} \mathrm{Cs}$ is mostly confined to the Pacific Ocean region because this process only acts upon particles in the boundary layer. Only the radioactive particles that escape towards the free troposphere can be transported over much larger distances. Since exchange between the boundary layer and free troposphere is mostly dependent on convection events, the particulate contaminants are to a large extent removed by the associated precipitation. This is much less the case for ${ }^{131} \mathrm{I}$, which has a low solubility, so that convection effectively redistributes this gas into the free troposphere where the wind speed is typically higher and transport distances larger.

Therefore, even though ${ }^{131}$ I has a relatively short halflife, meteorological conditions associated with convection and vertical mixing over the Pacific Ocean promote its longdistance transport so that it contributes to radioactivity deposition worldwide (Fig. 6, bottom panel). Our model results suggest that the plumes that traversed the Pacific Ocean caused significant deposition of radioactivity over continental North America, in particular western USA, western Canada and eastern USA $\left(>100 \mathrm{Bqm}^{-2}\right)$. Our model results also show substantial deposition of radionuclides in regions southwest of Japan, e.g., around the Philippines (Fig. 7, upper panel). Two weeks after the accident, all operational CTBTO stations in the northern hemisphere had reported at least one ${ }^{131}$ I detection (Stoehlker et al., 2011).

Detailed budget analysis, based on the T255 resolution model results, shows that $29.3 \mathrm{PBq}$ of the nominal total of 36.7 $\mathrm{PBq}{ }^{137} \mathrm{Cs}$ released by Fukushima was deposited to the ocean (equivalent to $\sim 80 \%$ ) and the rest over land, mostly in Japan. This is in agreement to the budget analysis performed by Morino et al. (2011) which indicated that $22 \%$ of ${ }^{137} \mathrm{Cs}$ was deposited over land in Japan, and the rest deposited over the ocean (or transported outside of their $700 \times 700 \mathrm{~km}^{2}$ model domain) between 11-30 March 2011 and the budget analysis performed by Ten Hoeve and Jacobson (2012), indicating that $19 \%$ of the total worldwide deposited ${ }^{137} \mathrm{Cs}$ was over land and the remaining $81 \%$ over the oceans. We find that only a small fraction (less than $1 \%$ ) was deposited within the Arctic circle (at latitudes higher than $67^{\circ} \mathrm{N}$ ). We estimate that of the total emitted amount of radioactivity,
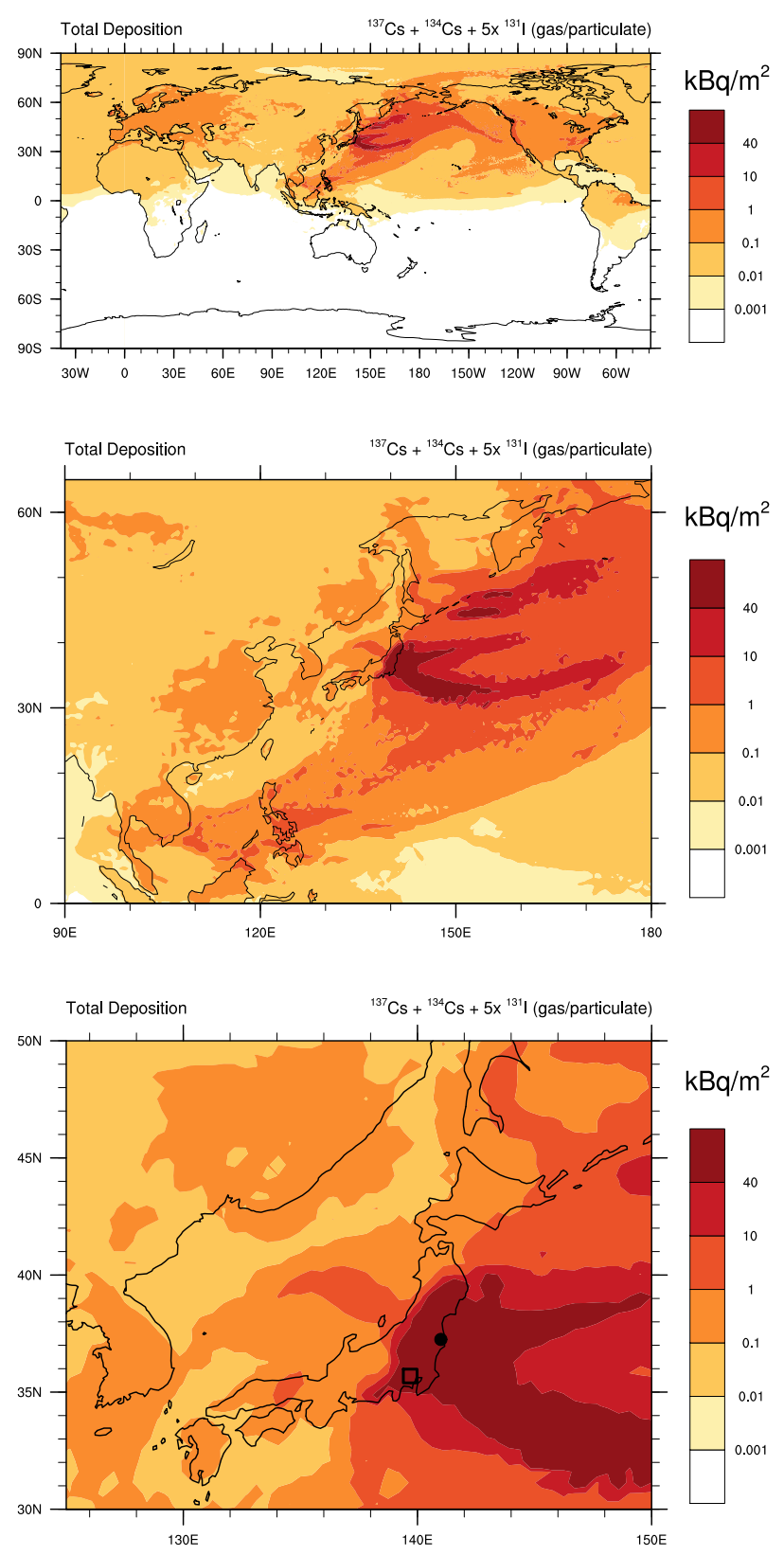

Fig. 8. Global (top), and regional (middle: Asia Pacific; Bottom: Japan) combined total deposition of ${ }^{137}$ Cs (Stohl et al., 2012) and

${ }^{131} \mathrm{I}$ in Bq, based on a sensitivity simulation with 5 times enhanced

${ }^{131}$ I emissions (750 PBq; Chino et al., 2011), also including ${ }^{134} \mathrm{Cs}$ and particulate ${ }^{131} \mathrm{I}$ deposition scaled to ${ }^{137} \mathrm{Cs}$. The black point marks the location of the Fukushima nuclear power plant and the rectangle the Tokyo metropolitan area. Contours are on a logarithmic scale. The $40 \mathrm{kBq} \mathrm{m}^{-2}$ contour lines signify areas that received total deposition greater than the contamination activity level defined by the International Atomic Energy Agency (IAEA) (2005, 2009). 


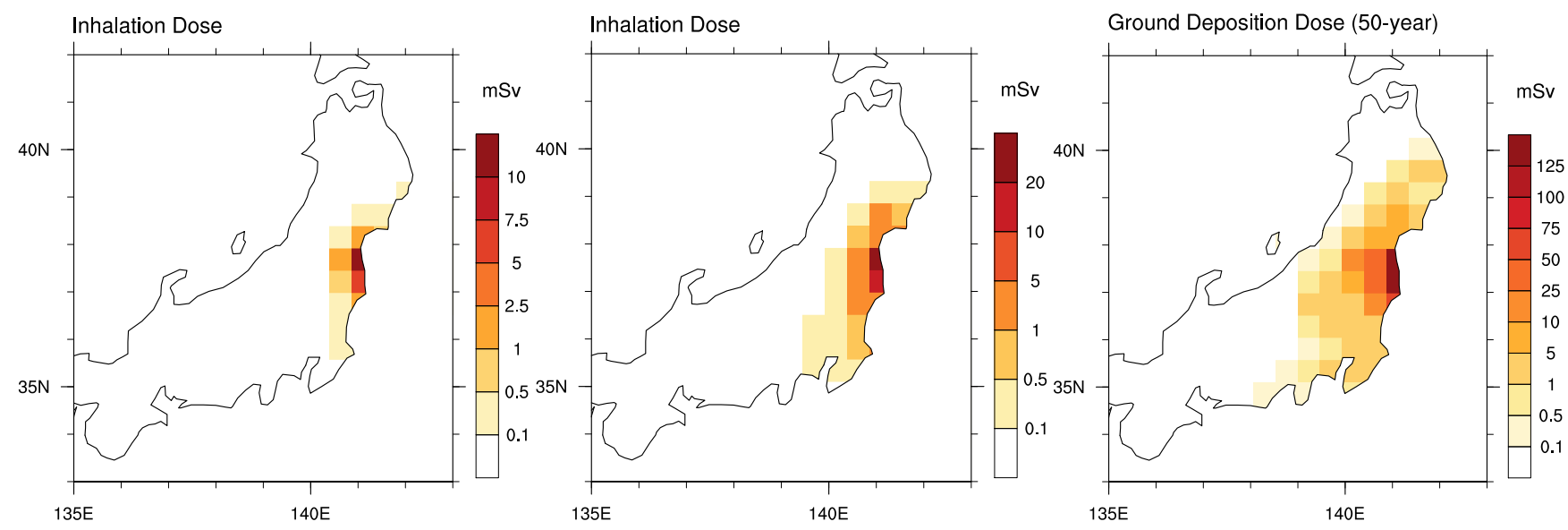

Fig. 9. Effective dose from the inhalation of airborne radionuclides for the nominal emission dataset (left); inhalation dose sensitivity test for the ${ }^{131} \mathrm{I}$ emission scaled by factor 5 (middle); and fifty-year dose from the ground deposition of ${ }^{131} \mathrm{I},{ }^{134} \mathrm{Cs}$ and ${ }^{137} \mathrm{Cs}$ (right) based on dose factors by the IAEA (2009).

approximately $40 \%, 60 \%$, and $75 \%$ were deposited in regions at distances of $5^{\circ}, 10^{\circ}$ and $20^{\circ}$ in latitude and longitude from the location of the source.

The regional deposition distribution of the sum of ${ }^{137} \mathrm{Cs}$ and ${ }^{131} \mathrm{I}$ at different scales is shown in Fig. 7. We estimate that the land area affected by the deposition of radioactivity (by both compounds) in excess of $40 \mathrm{kBq} \mathrm{m}^{-2}$ is approximately $34,000 \mathrm{~km}^{2}$. Using the population data from (CIESIN/CIAT/SEDAC, 2005) (referring to the year 2010), this part of Japan is inhabited by $\sim 9.4$ million people. The surface area that received a total deposition greater than $10 \mathrm{kBq} \mathrm{m}^{-2}$ encompasses parts of the Tokyo metropolitan area, and approximately covers $60,000 \mathrm{~km}^{2}$, being inhabited by $\sim 46$ million people. We emphasize that this is based on the emission of $150 \mathrm{PBq}{ }^{131}$ I estimated by Chino et al. (2011), which might actually be a factor of five too low.

To test the potential of a larger source than $150 \mathrm{PBq}{ }^{131} \mathrm{I}$, and the contribution of particulate ${ }^{131} \mathrm{I}$ deposition and other radionuclides we performed a sensitivity test by applying 5 times higher emissions, based on the emissions estimate uncertainty by Chino et al. (2011). In the sensitivity test ${ }^{134} \mathrm{Cs}$ and particulate ${ }^{131} \mathrm{I}$ concentrations and deposition rates were scaled with ${ }^{137} \mathrm{Cs}$, assuming a ${ }^{134} \mathrm{Cs}$ to ${ }^{137} \mathrm{Cs}$ activity ratio of 0.9 (Ten Hoeve and Jacobson, 2012) and a factor of 4 gaseous to particulate ${ }^{131} \mathrm{I}$ in the atmosphere. Figure 8 shows the results, indicating significantly larger and perhaps more realistic deposition of radioactivity worldwide (upper panel). The regional and national deposition patterns are illustrated by the middle and lower panel, respectively. If this would be correct, a large inhabited area would be contaminated by more than $40 \mathrm{kBq} \mathrm{m}^{-2}$, including the Tokyo metropolitan area. Although this large ${ }^{131} \mathrm{I}$ source is speculative, it seems more realistic than the low estimate of $150 \mathrm{PBq}$ by Chino et al. (2011). It should be noted that the assumption of $25 \%{ }^{131} \mathrm{I}$ in the particulate phase leads to a reduction of the ${ }^{131}$ I lifetime in the atmosphere. If this were correct, the model underestimate of ${ }^{131}$ I concentrations compared to the CTBTO measurements would even be larger, providing additional justification for a much larger source than $150 \mathrm{PBq}$. Further study will be needed to resolve this important issue.

\subsection{Doses from Inhalation and Ground Deposition}

We estimated the cumulative doses due to inhalation over the simulation period (11 March-31 May 2011) as well as the effective doses over 50 years from ground contamination by applying conversion factors for ${ }^{137} \mathrm{Cs},{ }^{134} \mathrm{Cs}$ and ${ }^{131} \mathrm{I}$ recommended by the International Atomic Energy Agency (IAEA, 2009, Appendix I). The ${ }^{134}$ Cs concentration and deposition rate in each grid cell was scaled from ${ }^{137} \mathrm{Cs}$, assuming the ${ }^{134} \mathrm{Cs}$ to ${ }^{137} \mathrm{Cs}$ activity ratio of 0.9 , based on CTBTO observations (Ten Hoeve and Jacobson, 2012). The contribution by noble gases, including ${ }^{133} \mathrm{Xe}$, can be neglected as the dose ratios relative to ${ }^{131} \mathrm{I}$ are effectively zero.

The inhalation doses are converted from model calculated concentrations $\left(\mathrm{Bq} \mathrm{s} \mathrm{m}^{-3}\right)$ into $\mathrm{Sv}$ (Sievert), applying the factors $1.29 \times 10^{-11}, 6.60 \times 10^{-12}$ and $2.44 \times 10^{-12}$ for ${ }^{137} \mathrm{Cs}$, ${ }^{134} \mathrm{Cs}$ and ${ }^{131} \mathrm{I}$, respectively. The results are shown in Fig. 9. Our calculations do not comprise dosages to individuals from the ingestion of radionuclides, based on the assumption that food intervention levels prevent such exposure. The maximum cumulative effective dose from inhalation in Japan is found to exceed $10 \mathrm{mSv}$ for the nominal emissions (36.7 PBq ${ }^{137} \mathrm{Cs}$ and $150 \mathrm{PBq}{ }^{131} \mathrm{I}$ ) and $20 \mathrm{mSv}$ for the sensitivity test with five times higher ${ }^{131} \mathrm{I}$ emissions, i.e., the upper bound of the emissions uncertainty indicated by Chino et al. (2011). These estimates apply to adult members of the general public and not to workers who received higher doses in contaminated facilities. 
Further, we calculated the effective dose to the public from exposure to ground contamination due to the deposition of ${ }^{137} \mathrm{Cs},{ }^{134} \mathrm{Cs}$ and ${ }^{131} \mathrm{I}$. The 50 -year ground deposition doses are derived from the conversion of deposited radioactivity in $\mathrm{Bqm}^{-2}$ into an effective dose in Sv, applying the factors $1.30 \times 10^{-7}, 5.10 \times 10^{-9}$ and $2.70 \times 10^{-10}$ for ${ }^{137} \mathrm{Cs}$, ${ }^{134} \mathrm{Cs}$ and ${ }^{131} \mathrm{I}$, respectively (IAEA, 2009). The cumulative effective dose from radioactive compounds remaining on the ground for a period of 50 years is shown in the right panel of Fig. 9. The 50-year effective dose is dominated by the effects of ${ }^{137} \mathrm{Cs}$ and is less sensitive to the large uncertainty of the deposited amounts of ${ }^{131} \mathrm{I}$ and ${ }^{134} \mathrm{Cs}$. The sensitivity of these dose estimates to the radionuclide ${ }^{132} \mathrm{Te}$ is expected to be low, because even though the radioactivity ratio of ${ }^{131} \mathrm{I}:\left({ }^{131} \mathrm{I}+{ }^{132} \mathrm{Te}\right):{ }^{134} \mathrm{Cs}:{ }^{137} \mathrm{Cs}=1: 2: 0.1: 0.1$ (Katata et al., 2011), the dose factors from ground deposition and inhalation are at least 3 orders of magnitude lower.

The geographic distribution of dose estimates within the land area of Japan is associated with a high degree of uncertainty, due to the spatial resolution of our model. A nested regional model can be used in a future study to improve upon the estimates by the use of more detailed land model and a finer grid. In Fig. 9 we show the horizontal resolution to emphasize the relatively coarse grid of our model, about $50 \mathrm{~km}$, which for example cannot reflect the complex terrain around the Dai-ichi accident site. Nevertheless, since the ${ }^{133} \mathrm{Xe}$ simulations have shown that transport over large distances is simulated accurately by our model, we may assume that this also applies to shorter distances of $50 \mathrm{~km}$ upward.

\section{Conclusions}

The release of radioactivity from the Fukushima Dai-ichi nuclear power plant accident and the atmospheric transport and deposition patterns between March and May 2011 were simulated using the EMAC atmospheric chemistry - general circulation model at different resolutions (T255 and T106, equivalent to $\sim 50 \mathrm{~km}$ and $\sim 110 \mathrm{~km}$ Gaussian grid resolution respectively). The atmospheric dynamics were nudged towards ERA-Interim reanalysis data of the ECMWF, available at $\mathrm{T} 255$ resolution.

We initialized our model by applying emissions of the inert noble gas ${ }^{133} \mathrm{Xe}$ and the semi-volatile gases ${ }^{131} \mathrm{I}$ and ${ }^{137} \mathrm{Cs}$. In our model, ceasium attaches to ambient aerosol particles, whereas the iodine remains in the gas phase. The source terms are based on estimates from the literature, produced by inverse modelling and reverse estimation techniques. There are significant differences and large uncertainties in the total amount and temporal release of radionuclides between the presently available estimates. Removal processes through precipitation, particle sedimentation, dry deposition and radioactive decay were taken into account.

Modeled surface concentrations were compared to station observations by the Comprehensive Nuclear-Test-Ban Treaty
Organisation (CTBTO) global monitoring network for a selected number of stations. We obtained good agreement with measurements of ${ }^{133} \mathrm{Xe}$, at both T255 and T106 resolution. The comparison for ${ }^{137} \mathrm{Cs}$ is less favorable, though not systematically biased based on the ${ }^{137} \mathrm{Cs}$ emission estimate of 36.7 (20.1-53.1) PBq by Stohl et al. (2012). This is equivalent to somewhat less than half the ${ }^{137} \mathrm{Cs}$ source by Chernobyl (85 PBq, International Atomic Energy Agency (IAEA) (2006)). The estimate of 13 PBq by Chino et al. (2011) (revised to $8.8 \mathrm{PBq}$ by Terada et al. (2012) and confirmed as a lower bound of 12 PBq by Winiarek et al. (2012), with an upper bound of $210 \mathrm{PBq}$, was also included in our comparison.

The model calculated deposition patterns show that most of the radioactivity which was released to the atmosphere ended in the Pacific Ocean (about $80 \%$ ), in agreement with other studies (Morino et al., 2011; Ten Hoeve and Jacobson, 2012). Although the prevailing wind direction during the accident was in easterly direction, some of the atmospheric radioactivity was transported toward the west and southwest, and deposited in Japan and to a lesser extent reached the Philippines. Based on the above mentioned emission estimates, we calculated that an area of Japan of $34,000 \mathrm{~km}^{2}$ was contaminated by more than $40 \mathrm{kBqm}^{-2}$ of ${ }^{137} \mathrm{Cs}$ and ${ }^{131} \mathrm{I}$, to which $\sim 9.4$ million people were exposed. Our model results indicate that a surface area of $60,000 \mathrm{~km}^{2}$ received a total deposition greater than $10 \mathrm{kBq} \mathrm{m}^{-2}$, a region inhabited by $\sim 46$ million people.

The source term of $150 \mathrm{PBq}{ }^{131} \mathrm{I}$ applied in our model, based on Chino et al. (2011), is associated with a systematic underestimate of simulated concentrations compared to the CTBTO measurements. Therefore, we performed an ${ }^{131}$ I emissions sensitivity test, with a factor of five stronger source, i.e., the upper bound of the uncertainty range indicated by Chino et al. (2011). If this would be realistic, our model indicates that a relatively large and densely populated part of Japan including parts of the Tokyo metropolitan area has been contaminated by more than $40 \mathrm{kBq} \mathrm{m}^{-2}$. Additional work will be needed to estimate the ${ }^{131}$ I source more accurately.

Finally, we estimated the cumulative doses to the public due to the inhalation of radionuclides over the simulated time period (11 March-31 May 2011) and the effective doses over a 50-year period from ground contamination. The maximum inhalation dose around the Fukushima nuclear accident site is calculated to be $>10 \mathrm{mSv}$ for the nominal emissions case and $>20 \mathrm{mSv}$ for the sensitivity test to the emissions uncertainty by Chino et al. (2011) (five times higher ${ }^{131}$ I emissions). These estimates only include ${ }^{137} \mathrm{Cs}$ and ${ }^{131} \mathrm{I}$, and neglect other isotopes of caesium and iodine and other radionuclides such as ${ }^{132} \mathrm{Te}$. The maximum 50 -year dose due to ground contamination in the area around the Fukushima nuclear power plant is estimated to be $>125 \mathrm{mSv}$. This result is less sensitive to the high uncertainty of the ${ }^{131}$ I emissions since it is dominated by the deposition of caesium. 


\section{Supplementary material related to this article is available online at: http://www.atmos-chem-phys.net/13/ 1425/2013/acp-13-1425-2013-supplement.pdf.}

Acknowledgements. The research leading to these results has received funding from the European Research Council under the European Union's Seventh Framework Programme (FP7/20072013) / ERC grant agreement no 226144. Computational resources were provided by the LinkSCEEM project. We thank the International Data Centre (IDC) of the Provisional Technical Secretariat (PTS) for the CTBTO Preparatory Commission for producing and providing the radionuclide measurement data. We are most grateful for comments received by the CTBTO PTS on how to improve our manuscript. The Preparatory Commission for the Comprehensive Nuclear-Test-Ban Treaty Organization and its Provisional Technical Secretariat are not responsible for the views of the authors. The NCAR Command Language (NCL) (UCAR/NCAR/CISL/VETS, 2012) was used for data analysis and visualisation.

Edited by: Y. Balkanski

\section{References}

Anspaugh, L., Catlin, R., and Goldman, M.: The global impact of the Chernobyl reactor accident, Science, 242, 1513-1519, 1988.

Butler, D.: Radioactivity spreads in Japan, Nature, 471, 555-556, 2011.

Chino, M., Ishikawa, H., et al.: SPEEDI and WSPEEDI: Japanese emergency response systems to predict radiological impacts in local and workplace areas due to a nuclear accident, Radiat. Prot. Dosim., 50, 145-152, 1993.

Chino, M., Nakayama, H., Nagai, H., Terada, H., Katata, G., and Yamazawa, H.: Preliminary estimation of release amounts of 131I and 137Cs accidentally discharged from the Fukushima Daiichi nuclear power plant into the atmosphere, J. Nucl. Sci. Technol., 48, 1129-1134, 2011.

CIESIN/CIAT/SEDAC: Gridded Population of the World, Version 3 (GPWv3), http://sedac.ciesin.columbia.edu/gpw, 2005.

Hilton, J., Cambray, R., and Green, N.: Chemical fractionation of radioactive caesium in airborne particles containing bomb fallout, Chernobyl fallout and atmospheric material from the Sellafield site, J. Environ. Radioactiv., 15, 103-111, 1991.

IAEA: International Nuclear and Radiological Event Scale User Manual, Vienna, 2009.

International Atomic Energy Agency (IAEA): Regulations for the Safe Transport of Radioactive Material, IAEA Safety Requirements, no. TS-R-1, Vienna, 2005.

International Atomic Energy Agency (IAEA): Environmental Consequences of the Chernobyl Accident and Their Remediation: Twenty Years of Experience, IAEA, Vienna, 2006.

International Atomic Energy Agency (IAEA): Regulations for the Safe Transport of Radioactive Material, IAEA Safety Requirements, no. TS-R-1, Vienna, 2009.

Jeuken, A., Siegmund, P., Heijboer, L., Feichter, J., and Bengtsson, L.: On the potential assimilating meteorological analyses in a global model for the purpose of model validation, J. Geophys. Res., 101, 16939-16950, 1996.

Jöckel, P., Sander, R., Kerkweg, A., Tost, H., and Lelieveld, J.: Technical Note: The Modular Earth Submodel System (MESSy) - a new approach towards Earth System Modeling, Atmos. Chem. Phys., 5, 433-444, doi:10.5194/acp-5-433-2005, 2005.

Katata, G., Terada, H., Nagai, H., and Chino, M.: Numerical reconstruction of high dose rate zones due to the Fukushima Daiichi Nuclear Power Plant accident, J. Environ. Radioactiv., 111, 2-12, 2012.

Katata, G., Ota, M., Terada, H., Chino, M., and Nagai, H.: Atmospheric discharge and dispersion of radionuclides during the Fukushima Dai-ichi Nuclear Power Plant accident. Part I: Source term estimation and local-scale atmospheric dispersion in early phase of the accident, J. Environ. Radioactiv., 109, 103-113, 2012.

Kerkweg, A., Buchholz, J., Ganzeveld, L., Pozzer, A., Tost, H., and Jöckel, P.: Technical Note: An implementation of the dry removal processes DRY DEPosition and SEDImentation in the Modular Earth Submodel System (MESSy), Atmos. Chem. Phys., 6, 4617-4632, doi:10.5194/acp-6-4617-2006, 2006.

Lelieveld, J., Brühl, C., Jöckel, P., Steil, B., Crutzen, P. J., Fischer, H., Giorgetta, M. A., Hoor, P., Lawrence, M. G., Sausen, R., and Tost, H.: Stratospheric dryness: model simulations and satellite observations, Atmos. Chem. Phys., 7, 1313-1332, doi:10.5194/acp-7-1313-2007, 2007.

Masson, O., Baeza, A., Bieringer, J., Brudecki, K., Bucci, S., Cappai, M., Carvalho, F., Connan, O., Cosma, C., Dalheimer, A., et al.: Tracking of airborne radionuclides from the damaged Fukushima Dai-ichi nuclear reactors by European networks, Environ. Sci. Technol., 45, 7670-7677, 2011.

MEXT: Japanse Ministry of Education, Culture, Sports, Science and Technology, http://www.mext.go.jp/english, 2011.

Morino, Y., Ohara, T., and Nishizawa, M.: Atmospheric behavior, deposition, and budget of radioactive materials from the Fukushima Daiichi nuclear power plant in March 2011, Geophys. Res. Lett, 38, L00G11, doi: 10.1029/2011GL048689, 2011.

Roeckner, E., Bäuml, G., Bonaventura, L., Brokopf, R., Esch, M., Giorgetta, M., Hagemann, S., Kirchner, I., Kornblueh, L., Manzini, E., Rhodin, A., Schlese, U., Schulzweida, U., and Tompkins, A.: The atmospheric general circulation model ECHAM5.PART I: Model description, Technical report, Max Planck Institute for Meteorology, 2003.

Roeckner, E., Brokopf, R., Esch, M., Giorgetta, M., Hagemann, S., Kornblueh, L., Manzini, E., Schlese, U., and Schulzweida, U.: Sensitivity of simulated climate to horizontal and vertical resolution in the ECHAM5 atmosphere model, J. Clim., 19, 37713791, 2006.

Simmons, A., Uppala, S., Dee, D., and Kobayashi, S.: ERA-Interim: New ECMWF reanalysis products from 1989 onwards, ECMWF newsletter, 110, 25-35, 2007.

Stoehlker, U., Nikkinen, M., and Gheddou, A.: Detection of radionuclides emitted during the Fukushima nuclear accident with the CTBT radionuclide network, Monitoring Research Review: Ground-Based Nuclear Explosion Monitoring Technologies, 715-724, 2011.

Stohl, A., Hittenberger, M., and Wotawa, G.: Validation of the Lagrangian particle dispersion model FLEXPART against large- 
scale tracer experiment data, Atmos. Environ., 32, 4245-4264, 1998.

Stohl, A., Seibert, P., Wotawa, G., Arnold, D., Burkhart, J. F., Eckhardt, S., Tapia, C., Vargas, A., and Yasunari, T. J.: Xenon133 and caesium-137 releases into the atmosphere from the Fukushima Dai-ichi nuclear power plant: determination of the source term, atmospheric dispersion, and deposition, Atmos. Chem. Phys., 12, 2313-2343, doi:10.5194/acp-12-2313-2012, 2012.

Takemura, T., Nakamura, H., Takigawa, M., Kondo, H., Satomura, T., Miyasaka, T., and Nakajima, T.: A numerical simulation of global transport of atmospheric particles emitted from the Fukushima Daiichi Nuclear Power Plant, Sola, 7, 101-104, 2011.

Ten Hoeve, J. and Jacobson, M.: Worldwide health effects of the Fukushima Daiichi nuclear accident, Energ. Environ. Sci., 5, 8743-8757, 2012.

Terada, H., Katata, G., Chino, M., and Nagai, H.: Atmospheric discharge and dispersion of radionuclides during the Fukushima Dai-ichi Nuclear Power Plant accident. Part II: verification of the source term and analysis of regional-scale atmospheric dispersion, J. Environ. Radioactiv., 112, 141-154, 2012.
Tost, H., Jöckel, P., Kerkweg, A., Sander, R., and Lelieveld, J.: Technical note: A new comprehensive SCAVenging submodel for global atmospheric chemistry modelling, Atmos. Chem. Phys., 6, 565-574, doi:10.5194/acp-6-565-2006, 2006.

Tost, H., Jöckel, P., Kerkweg, A., Pozzer, A., Sander, R., and Lelieveld, J.: Global cloud and precipitation chemistry and wet deposition: tropospheric model simulations with ECHAM5/MESSy1, Atmos. Chem. Phys., 7, 2733-2757, doi:10.5194/acp-7-2733-2007, 2007.

UCAR/NCAR/CISL/VETS: The NCAR Command Language (Version 6.0.0) [Software], Boulder, Colorado, doi:10.5065/D6WD3XH5, http://dx.doi.org/10.5065/ D6WD3XH5, 2012.

Winiarek, V., Bocquet, M., Saunier, O., and Mathieu, A.: Estimation of errors in the inverse modeling of accidental release of atmospheric pollutant: Application to the reconstruction of the cesium-137 and iodine-131 source terms from the Fukushima Daiichi power plant, J. Geophys. Res., 117, D05122, doi:10.1029/2011JD016932, 2012. 